\title{
The Influence of green areas and roof albedos on air temperatures during Extreme Heat Events in Berlin, Germany
}

\author{
SEBASTIAN SCHUBERT* and SUSANNE GROSSMAN-CLARKE
}

Potsdam Institute for Climate Impact Research, Germany

(Manuscript received May 1, 2012; in revised form November 15, 2012; accepted November 19, 2012)

\begin{abstract}
The mesoscale atmospheric model COSMO-CLM (CCLM) with the Double Canyon Effect Parametrization Scheme (DCEP) is applied to investigate possible adaption measures to extreme heat events (EHEs) for the city of Berlin, Germany. The emphasis is on the effects of a modified urban vegetation cover and roof albedo on near-surface air temperatures. Five EHEs with a duration of 5 days or more are identified for the period 2000 to 2009. A reference simulation is carried out for each EHE with current vegetation cover, roof albedo and urban canopy parameters (UCPs), and is evaluated with temperature observations from weather stations in Berlin and its surroundings. The derivation of the UCPs from an impervious surface map and a 3-D building data set is detailed. Characteristics of the simulated urban heat island for each EHE are analysed in terms of these UCPs. In addition, six sensitivity runs are examined with a modified vegetation cover of each urban grid cell by $-25 \%$, $5 \%$ and $15 \%$, with a roof albedo increased to 0.40 and 0.65 , and with a combination of the largest vegetation cover and roof albedo, respectively. At the weather stations' grid cells, the results show a maximum of the average diurnal change in air temperature during each EHE of $0.82 \mathrm{~K}$ and $-0.48 \mathrm{~K}$ for the $-25 \%$ and $15 \%$ vegetation covers, $-0.50 \mathrm{~K}$ for the roof albedos of 0.65 , and $-0.63 \mathrm{~K}$ for the combined vegetation and albedo case. The largest effects on the air temperature are detected during midday.
\end{abstract}

Keywords: Extreme Heat Events, adaptation, Mesoscale Modelling, Urban Heat Island.

\section{Introduction}

In this study we estimate the influence of possible mitigation measures to Extreme Heat Events (EHE) for the city of Berlin, Germany. For a given building composition the major strategies to reduce urban air temperatures include the increase of urban vegetation cover, roof top greening and reducing the albedo of impervious surfaces (RosENZWEIG et al., 2009). Here, we focus on modifications of vegetation cover as well as roof albedo, which influence urban air temperatures through evapotranspiration and reflection of radiation, respectively. This can lead to a reduced sensible heat flux and the amount of heat stored in urban surfaces, with a subsequent cooling of the urban air (ROSENZWEIG et al., 2009). The atmospheric conditions during the EHEs are simulated using the mesoscale atmospheric model COSMO-CLM (CCLM) coupled with the urban Double Canyon Effect Parametrization Scheme (DCEP; SCHUBERT et al., 2012). DCEP is a so called "urban canopy model" (UCM) that mathematically describes the average effects of a configuration of buildings and streets on the atmosphere. Regional atmospheric models allow spatial resolutions as high as a few hundred meters. Heterogeneities of urban land cover and their influence on the atmosphere

\footnotetext{
*Corresponding author: Sebastian Schubert, Potsdam Institute for Climate Impact Research, P.O. Box 6012 03, 14412 Potsdam, Germany, e-mail: schubert@pik-potsdam.de
}

can therefore be described by the models on that scale. However, the airflow around individual buildings and roads cannot be resolved.

Several studies demonstrated the potential use of regional atmospheric modeling for urban heat island (UHI) mitigation and air quality regulatory purposes by means of applying state-of-the-art UCMs with mesoscale meteorological and air quality models (TAHA, 2008; KIKEGAWA et al., 2003; SAILOR and DIETSCH, 2007; ROSENZWEIG et al., 2009; KRAYENHOFF and VOOGT, 2010; SAlamanCA et al., 2011; MASSON et al., 2012). For example, TAHA (2008) showed for Sacramento (California, USA) a potential UHI mitigation of up to $3{ }^{\circ} \mathrm{C}$ in response to increased albedo of roof, walls and roads and urban vegetation cover. Also according to these simulations, the ozone concentration could be reduced in most areas of the city. KRAYENHOFF and VOOGT (2010) estimated the reduction of the maximum daytime air temperature in downtown Chicago (Illinois, USA) during a clear summer day connected to a change of the roof albedo from 0.06 to 0.65 to be about $1 \mathrm{~K}$. SALAMANCA et al. (2011) showed a considerable reduction in the simulated summer UHI and energy consumption for Madrid (Spain) due to a reduction in roof albedos and anthropogenic heating.

In order to estimate the cooling effect of vegetation in Berlin, we compare results of a reference simulation with those from simulations that are characterized by increased or decreased vegetation fractions. 
The reference simulation is based on the current spatial distribution of vegetation cover in Berlin. Furthermore, we compare results from simulations with average surface albedos, resulting from hyperspectral measurements in Berlin, with simulations representing the application of high-albedo roof surface coatings (BRETZ and AKBARI, 1997). Urban canopy parameters are derived from an extensive 3-D building data set (JUNG, 2009) and are used in all simulations. We also use these parameters to analyse the spatial structure of the simulated UHI.

First, we introduce the models CCLM and DCEP. Second, we describe the derivation of urban input parameters for the city of Berlin and third, we present results of the reference simulations and simulations with modified urban parameters. Last, a summary with conclusions is given.

\section{Model description and setup}

The CCLM is a non-hydrostatic limited-area regional climate model developed from the operational weather forecast Local Model (LM) of the German Weather Service (STEPPELER et al., 2003) by the CLM-Community ${ }^{1}$. Since 2005 it has been the community-model of the German climate research. Meanwhile it is used and further developed by several other weather services organized in the COnsortium for Small-scale MOdelling (COSMO). In a sense the CCLM model system is a unified model system for Numerical Weather Prediction and Regional Climate Modelling.

Currently in the standard CCLM, cities are parameterized by means of a bulk-transfer scheme as natural land surfaces but with an increased surface roughness length $(1 \mathrm{~m})$, reduced plant cover fraction $(20 \%)$ and leaf area index $\left(1 \mathrm{~m}^{2} \mathrm{~m}^{-2}\right)$ in order to account for the increased vertical momentum flux and reduced evapotranspiration, respectively. The advantage of this approach is the relatively low demand on input parameters and the simplicity of its coupling with the atmospheric model (MASSON, 2006). However, this simple parameterization is not able to fully represent the characteristics of urban areas that influence the atmosphere (BEST, 2005), such as a considerable increase in heat storage and also small negative values of the nocturnal sensible heat flux directed towards the urban surfaces or even a positive sensible heat flux directed towards the atmosphere. Therefore, characteristics of the urban planetary boundary layer such as the UHI as well as a near-neutral nocturnal vertical temperature profile and its downwind advection cannot be simulated sufficiently well (BEST, 2005). Also, bulktransfer schemes do not resolve the vertical effects of buildings on the urban canopy air and often do not differentiate between several urban land use classes (LIU et al., 2006).

We therefore implemented the newly developed multilayer UCM DCEP, which is based on the Building Effect Parametrization Scheme BEP (MARTILLI et al.,

${ }^{1}$ http://www.clm-community.eu
2002), into the CCLM. As described in detail in SCHUBERT et al. (2012), in DCEP the fraction of a mesoscale model grid cell covered by impervious surfaces is conceptualized as multiple series of identical street canyon elements. Each series of canyon elements is characterized by a particular street direction. The basic street canyon element in BEP consists of one road surface, one row of buildings and two walls. In DCEP, another canyon is added, thus allowing to include the radiative exchange of roofs with other urban surfaces. In addition, DCEP treats diffuse and direct solar radiation separately and closes the radiative energy balance. The former allows for the calculation of separate effective urban albedo for diffuse and direct solar radiation and, thus, for a more detailed coupling with CCLM. In BEP, the incoming diffuse radiation from the sky is overestimated depending on the variability of the building heights in a grid cell. For Berlin, this amounts to about $10 \%$ but larger values can also be observed (SCHUBERT et al., 2012). Similar to BEP, however, DCEP does not currently account for evaporation fluxes from the urban surfaces. While this does not pose any problem for the considered EHEs, the application to other periods is limited by that.

For our sensitivity study we apply the coupled CCLM/DCEP model to the region around Berlin for EHEs during the period 2000-2009. To identify the EHEs, we use the criterion by HUTH et al. (2000) and MEEHL and TEBALDI (2004). They define an EHE as the longest period of consecutive days with (i) the daily maximum temperature larger than a threshold temperature $T_{1}$ for at least 3 days, (ii) the average daily maximum temperature above $T_{1}$ and (iii) the maximum temperature of every day above the threshold temperature $T_{2}$. For the application to Berlin, we base the choice of $T_{1}$ and $T_{2}$ on the statistics of the meteorological data obtained at two airport weather stations at Berlin-Tegel and Berlin-Tempelhof for the period 1970-1999. We define $T_{1}$ and $T_{2}$ as the 95th and 81st percentile, respectively, of the distribution, resulting in the same values for both weather stations: $T_{1}=30.9{ }^{\circ} \mathrm{C}$ and $T_{2}=27.3{ }^{\circ} \mathrm{C}$. For this study, we focus on heat waves with a length of at least 5 days: 2002/07/28-2002/08/01, 2003/08/01-2003/ 08/13, 2006/07/01-2006/07/07 and 2006/07/17-2006/ 07/28 based on the statistics of both stations. An EHE is also identified for 2008, but depending on the station for a slightly different time period: 2008/07/25-2008/ 08/01 (Tegel) and 2008/07/24-2008/07/29 (Tempelhof).

We conduct 9 day CCLM simulations with one way nested grids of resolutions of approx. $25 \mathrm{~km}$ (without DCEP), $7 \mathrm{~km}$ (without DCEP), $2.8 \mathrm{~km}$ (with and without DCEP) and $1 \mathrm{~km}$ (with and without DCEP) for the EHEs listed above starting 2 days before the identified beginning of the EHE (Figure 1). The remaining one week periods are included in our analysis for each EHE.

The initial and 6 hourly boundary conditions are provided by ERA-Interim reanalysis data (DEE et al., 2011). All nesting steps use spectral nudging (ROCKEL et al., 2008). The initial soil water content for the $25 \mathrm{~km}$ 


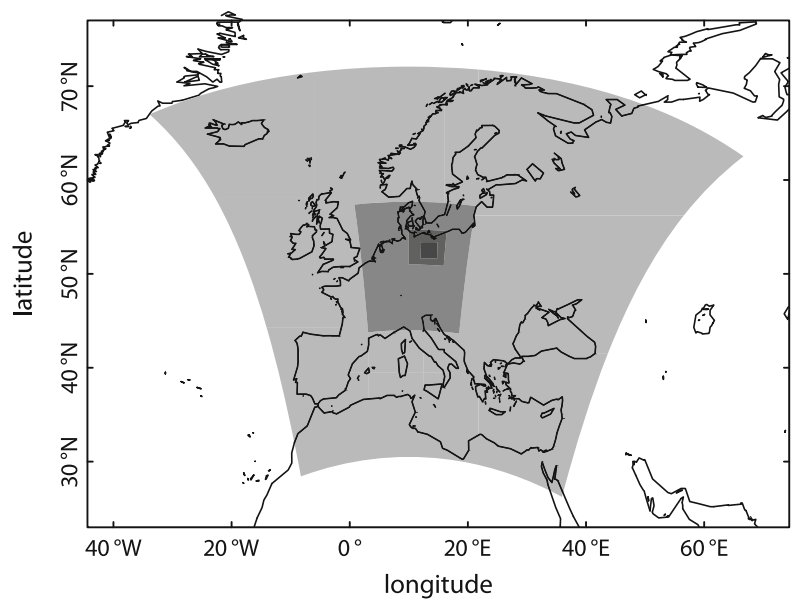

Figure 1: Nested domains of the downscaling for Berlin, Germany. The resolutions are with decreasing domain size $25 \mathrm{~km}, 7 \mathrm{~km}$, $2.8 \mathrm{~km}$ and $1 \mathrm{~km}$.

resolution run, however, is taken from a simulation with the same setup as the $25 \mathrm{~km}$ run starting in January 1995. We found that the ERA-Interim soil water content is too high for the soil model of CCLM and thus resulted in too low air temperatures.

The orography, monthly vegetation and soil parameters are provided by the preprocessor of CCLM (SMIATEK et al., 2008). This data set provides vegetation parameters and roughness length in the area of Berlin appropriate for the bulk-transfer scheme. With DCEP, the preprocessor parameters represent only the vegetation part in a grid cell. Thus, we replace the data in Berlin with parameters for July and August from the surroundings of Berlin: a leaf area index of $3.5 \mathrm{~m}^{2} \mathrm{~m}^{-2}$ and $2.9 \mathrm{~m}^{2} \mathrm{~m}^{-2}$; a plant cover fraction of 0.88 and 0.82 ; a root depth of $1.5 \mathrm{~m}$; a roughness length of $0.13 \mathrm{~m}$ and $0.08 \mathrm{~m}$.

The urban scheme DCEP is run with different setups for every simulation period:

1. The reference period represents the current state of Berlin. It uses the morphological input parameters explained in the next section and urban surface parameters for roof (R), wall (W) and street surfaces $(\mathrm{G})$ following the propositions by MARTILLI et al. (2002): an emissivity of $\epsilon_{\mathrm{R}}=\epsilon_{\mathrm{W}}=0.90, \epsilon_{\mathrm{G}}=0.95$ and an thermal diffusivity of $K_{\mathrm{R}}=K_{\mathrm{W}}=0.67 \times 10^{-6} \mathrm{~m}^{2} \mathrm{~s}^{-1}$, $K_{\mathrm{G}}=0.29 \times 10^{-6} \mathrm{~m}^{2} \mathrm{~s}^{-1}$, where every layer of each surface element is assumed to have the same respective $K$. The albedo for roof and street surfaces is based on average values of a hyperspectral measurements (ROESSNER et al., 2011): $\alpha_{\mathrm{R}}=0.163, \alpha_{\mathrm{G}}=0.162$; in addition we assumed $\alpha_{\mathrm{W}}=0.162$. Furthermore, the outermost layer of each urban surface element is characterized by the volumetric specific heat capacity, for which we use an increased value of $c_{\mathrm{R}}=c_{\mathrm{W}}$ $=c_{\mathrm{G}}=2.3 \times 10^{6} \mathrm{~J} \mathrm{~m}^{-3} \mathrm{~K}^{-1}$.

2. Compared to the reference simulation, the natural surface fraction $f_{\text {nat }} \equiv 1-f_{\text {urb }}$ of each urban grid cell is modified by a certain fraction $\delta f_{\text {nat }} \equiv \Delta f_{\text {nat }} / f_{\text {nat }}$. $f_{\text {nat }}$ multiplied by the plant cover fraction yields the vegetation fraction $f_{\text {veg }}$ of a grid cell. Since an annual cycle of the plant cover fraction is assumed in CCLM, a constant $\delta f_{\text {nat }}$ results in a varying absolute modification of $f_{\text {veg }}$ but in a constant relative change: $\delta f_{\text {nat }}=\delta f_{\text {veg }}$. In the following, three different modifications of $f_{\text {nat }}$ are analysed: $\delta f_{\text {nat }}=-25 \%$, $\delta f_{\text {nat }}=5 \%$ and $\delta f_{\text {nat }}=15 \%$. These model runs are named $\mathrm{V}-25, \mathrm{~V}+05$ and $\mathrm{V}+15$ in the following.

3. Based on the setup of the reference simulation, the roof albedo is increased to 0.40 and 0.65 with the corresponding runs AR40 and AR65, respectively. BRETZ and AKBARI (1997) showed that even a large albedo of 0.65 is maintainable.

4. Combined V+15 and AR65, which is called VAR run.

\section{Derivation and analysis of urban canopy parameters in Berlin}

For the reference simulation we derive various urban canopy parameters for every mesoscale grid cell. For that we use an impervious surface data set of Berlin as well as a 3-D building data set with over 460000 buildings (JUNG, 2009) in the City Geography Markup Language level of detail 2 format (CityGML LOD2) defined in OGC (2008). In this format, buildings are modelled with polygons, which are semantically distinguished between ground, wall and roof surfaces. In the following, the derivation of the effective urban parameters is explained.

The canyon length $D$ is set to the average street length in a grid cell and is thus defined by the CCLM resolution. Since the urban part of the grid cell in DCEP represents a $100 \%$ impervious surface, we set the urban fraction $f_{\text {urb }}$ of a grid cell to the impervious surface coverage of the cell (Figure 2a), e.g. a grid cell with 70\% impervious surfaces is represented as $70 \%$ urban and $30 \%$ natural in the model. The fraction cover of buildings $f_{\mathrm{b}}$ is given by the area of the building's ground surfaces (Figure 2b). With that, the fraction cover of the street surfaces is given by $f_{\text {str }}=f_{\text {urb }}-f_{\mathrm{b}}$. For Berlin, we find a maximum $f_{\text {urb }}$ and $f_{\mathrm{b}}$ of 0.85 and 0.56 , respectively.

The canyon angle of a wall surface is defined by the normal of that surface projected onto the horizontal plane. Weighting the angles with the corresponing wall area yields the distributions of street directions. For this study, we project every street onto the four directions north-west-south-east, north-south, north-east-southwest and east-west. With these directions we find that the distribution of street directions is highly correlated for directions that are perpendicular of each other. We define the correlation coefficient between the fraction of direction $a$ and $b$ by

$$
r(a, b) \equiv \frac{{\overline{\left(a-\bar{a}^{f}\right)\left(b-\bar{b}^{f}\right)}}^{f}}{s_{a} s_{b}} \text { with } \quad s_{i} \equiv \sqrt{{\overline{\left(i-\bar{i}^{f}\right)^{2}}}^{f}},
$$




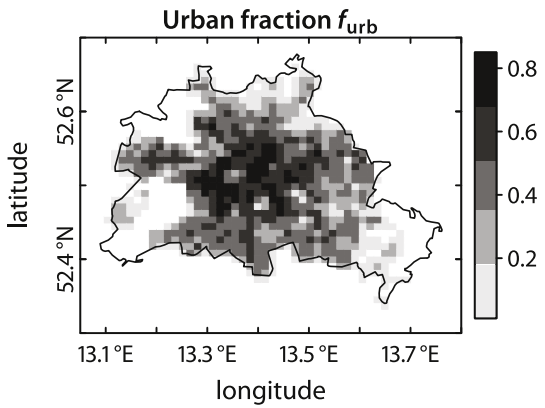

(a)

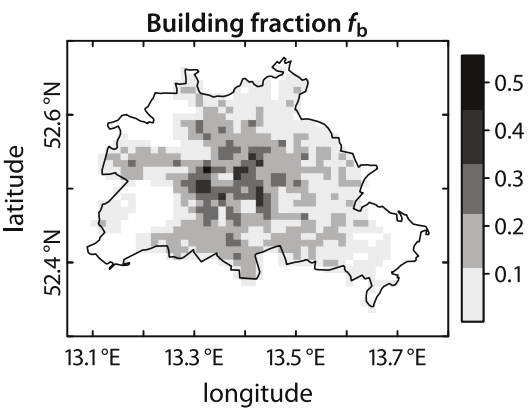

(b)

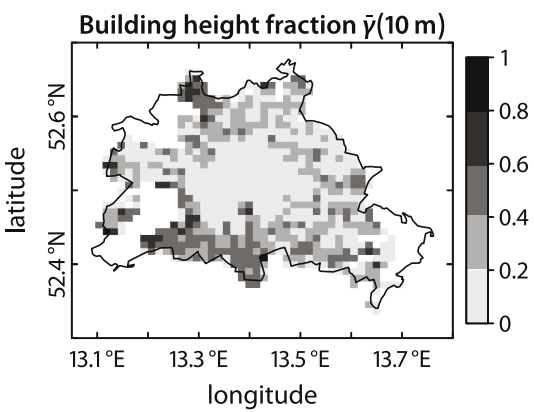

(c)

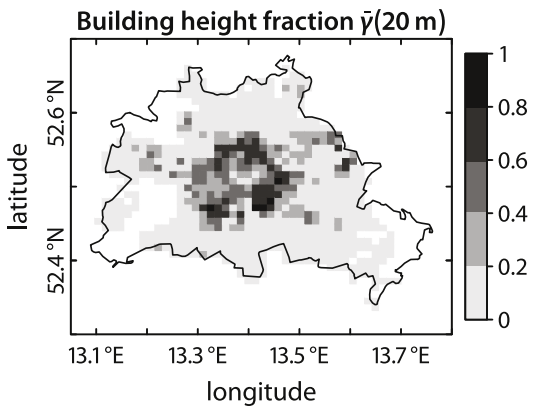

(d)

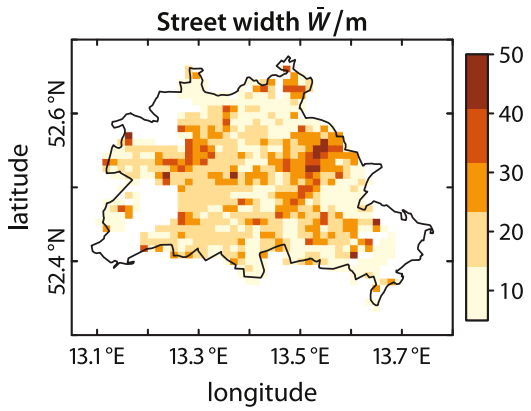

(e)

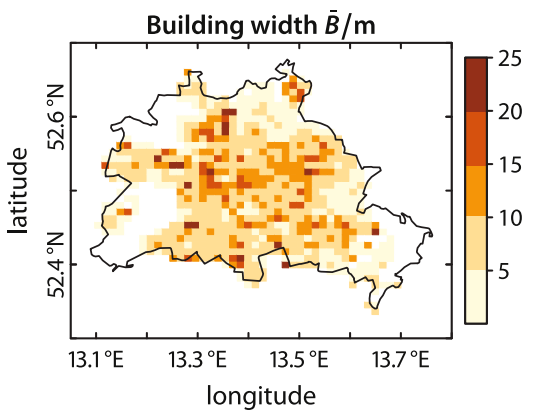

(f)

Figure 2: Urban canopy parameters derived from an impervious surface map and a 3-D building data set for Berlin at a resolution of $1 \mathrm{~km}$. The values in (c)-(f) are averages over all considered street directions.

where ${ }^{-f}$ indicates the spatial average weighted with the

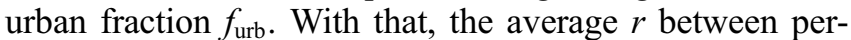
pendicular directions is 0.95 whereas it is -0.97 for directions not perpendicular.

The building height probability $\gamma(h)$ is determined by the distribution of building heights in the data set weighted by the respective ground area. Here, the building height is defined as the average height of the roof surfaces. Figures $2 \mathrm{c}$ and $2 \mathrm{~d}$ show the spatial distribution of the fraction of buildings at a height of $10 \mathrm{~m}$ and $20 \mathrm{~m}$, respectively, averaged over all street directions.

For each street direction in each grid cell, the street width $W$ is the weighted average of the distances $W_{i}$ :

$$
W=\frac{1}{\sum_{i} A_{i}} \sum_{i} W_{i} A_{i}
$$

where $A_{i}$ is the area of wall element $i . W_{i}$ is the weighted average distance between wall $i$ and the nearest visible walls $j$ :

$W_{i}=\frac{1}{\sum_{j} A_{j}} \sum_{j=1}^{n_{i}} W_{i j} A_{j}$ with $n_{i}$ the smallest value fulfilling

$$
\sum_{j=1}^{n_{i}} A_{j} \geq A_{i} \text { and } W_{i 1} \leq W_{i 2} \leq \ldots
$$

We define the distance $W_{i j}$ between two wall areas $i$ and $j$ as the distance between their centroids if the line between the centroids is unobstructed. The specifications in Equation (3.3) ensures that a sufficient number of nearest wall elements $j$ are considered.

Figure $2 \mathrm{e}$ shows the resulting street widths averaged over all street directions. The spatial average amounts to $\bar{W}^{f}=18.7 \mathrm{~m}$. The building width $B$ follows directly from the requirement that the total building and street surfaces of the simplified model equal that of the input data (MARTILLI, 2009):

$$
\frac{B}{W}=\frac{f_{\mathrm{b}}}{f_{\mathrm{str}}} .
$$

This results in the spatial distribution shown in Figure $2 \mathrm{f}$ $\left(\bar{B}^{f}=8.8 \mathrm{~m}\right)$.

\section{Results and discussion}

The CCLM/DCEP performance and the sensitivity to adaptation measures are evaluated in terms of the simulated air temperatures at $2 \mathrm{~m}$ above ground $\left(T_{2 \mathrm{~m}}\right)$ at surface weather stations in Berlin and its surroundings (Figure 3). The $2 \mathrm{~m}$ temperature in CCLM/DCEP is calculated from the surface temperature and the air temperature of the lowest model, $T_{1}$, using the atmospheric resistance for scalars of the roughness layer, $r_{\mathrm{S} \rightarrow 0}^{\mathrm{h}}$, and the resistance for scalars of the constant-flux layer above up to a height of $2 \mathrm{~m}, r_{0 \rightarrow 2 \mathrm{~m}}^{\mathrm{h}}$ (cf. DOMS et al., 2011; RASCHENDORFER, 2012). Since $T_{1}$ represents the grid cell average atmospheric air temperature (at a height of about $10 \mathrm{~m}$ in our case), only the surface temperature 


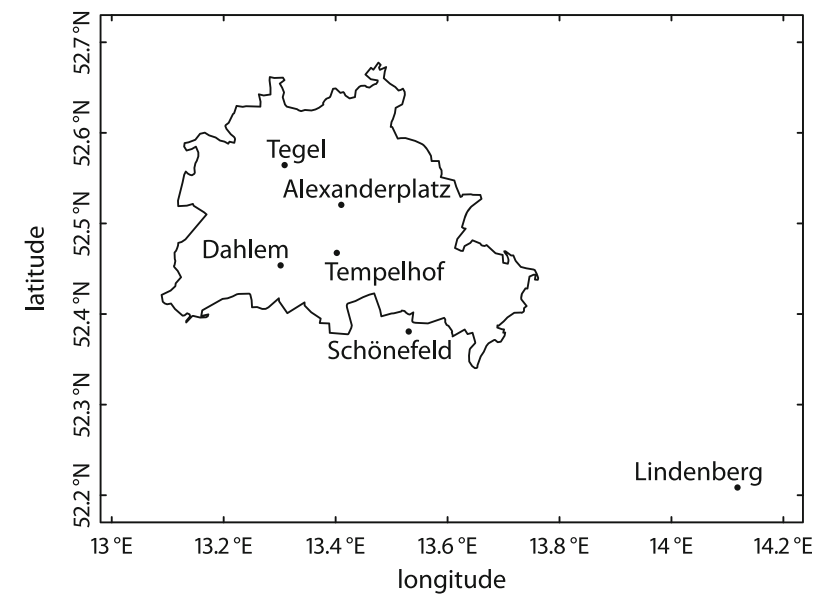

Figure 3: Locations of measurement sites in Berlin and vicinity from which $2 \mathrm{~m}$ temperature measurements are used for CCLM evaluation. The area of Berlin is outlined.

needs to be averaged for a grid cell average $2 \mathrm{~m}$ temperature. Thus,

$$
\begin{aligned}
& T_{2 \mathrm{~m}}=\left(f_{\text {nat }} T_{\mathrm{S}}+f_{\text {urb }} T_{\mathrm{G}}\right) \\
& +\frac{r_{\mathrm{S} \rightarrow 0}^{\mathrm{h}}+r_{0 \rightarrow 2 \mathrm{~m}}^{\mathrm{h}}}{r_{\mathrm{S} \rightarrow 1}^{\mathrm{h}}}\left[T_{1}-\left(f_{\text {nat }} T_{\mathrm{S}}+f_{\mathrm{urb}} T_{\mathrm{G}}\right)\right],
\end{aligned}
$$

where $T_{\mathrm{S}}$ is the surface temperature of natural surfaces and $T_{\mathrm{G}}$ is the temperature of the street surfaces in the urban part of the grid cell. The resistance $r_{\mathrm{S} \rightarrow 1}^{\mathrm{h}}$ for both layers is given by $r_{\mathrm{S} \rightarrow 1}^{\mathrm{h}}=r_{\mathrm{S} \rightarrow 0}^{\mathrm{h}}+r_{0 \rightarrow 1}^{\mathrm{h}}$. Here, $r_{0 \rightarrow 1}^{\mathrm{h}}$ is the total resistance of the complete constant-flux layer up to the height of the first model layer. The formulation of the original CCLM is recovered with $f_{\text {nat }}=1$ and $f_{\text {urb }}=0$.

The urban parameters used in the model grid cells of the stations' locations are listed in Table 1. The station at Berlin-Alexanderplatz $\left(52^{\circ} 31.232^{\prime} \mathrm{N}, 13^{\circ} 24.607^{\prime} \mathrm{E}\right)$ was situated next to the TV tower in the centre of the city during all considered EHEs. The very surrounding area consists of many small green patches and the building density apart from the TV tower is sparse resulting in a large street width. The station Berlin-Dahlem $\left(52^{\circ} 27.223^{\prime} \mathrm{N}, 13^{\circ} 18.104^{\prime} \mathrm{E}\right)$ in the south-west is situated at the border of the Botanical Garden and is thus dominated by the large green area directly surrounding it.

The direct surroundings of the stations at the (former) airports in Berlin $\left(52^{\circ} 33.865^{\prime} \mathrm{N}, 13^{\circ} 18.531^{\prime} \mathrm{E}\right.$ and $52^{\circ} 28.049^{\prime} \mathrm{N}, 13^{\circ} 24.126^{\prime} \mathrm{E}$, respectively) are characterized by large open areas resulting in the very small building widths in Table 1. For the simulations, the building width is set to $0 \mathrm{~m}$ in order to not unrealistically shadow the impervious surfaces in the respective areas. The station Berlin-Tegel is situated in the north-west and Berlin-Tempelhof in the southern centre of Berlin.

The station at the airport Schönefeld $\left(52^{\circ} 22.842^{\prime} \mathrm{N}\right.$, $13^{\circ} 31.834^{\prime} \mathrm{E}$ ) is located south-east of the border of Berlin and is characterized by similar conditions but is not considered urban in the simulation. Due to the close proximity to Berlin, Schönefeld is also affected by the urban area. The rural weather station at Lindenberg $\left(52^{\circ} 12.510^{\prime} \mathrm{N}, 14^{\circ} 7.080^{\prime} \mathrm{E}\right)$ is approx. $60 \mathrm{~km}$ away from Berlin's centre.

The locations of all weather stations are indicated by black dots in the following spatial plots.

\subsection{Evaluation of the model performance and simulated UHI characteristics}

The performance of the coupled CCLM/DCEP model is assessed based on the root-mean-square error (RMSE) and the mean-bias error (MBE) of $T_{2 \mathrm{~m}}$ for all introduced weather stations and EHEs (Table 2). Here, the results for Lindenberg represent the quality of the pure CCLM model because the corresponding grid cell is practically not influenced by the urban modifications by DCEP applied in Berlin. With the chosen set-up, the quality of the CCLM performance varies for the simulation periods: The model clearly performs best for the EHE of 2003 (RMSE of 1.1 and MBE of 0.6), while RMSE and MBE values as high as 2.4 and 1.7, respectively, were found for other periods. For all analysed EHEs, the CCLM/DCEP performance in the urban region is similar to that at rural Lindenberg in terms of RMSE and MBE. This indicates that DCEP captures the urban effects well. If CCLM simulates the regional weather reasonably well, the coupled model shows good results for Berlin and vice versa.

The deviations between observed and simulated values are larger for the Dahlem than for the other stations. This can be explained by the location of the Dahlem station in an extended park, whereas the model calculates the average grid cell $T_{2 \mathrm{~m}}$ comprising the influence of the urban and natural surfaces. This is confirmed when comparing the results with simulations in which Berlin is represented only by the bulk approach (also listed in Table 2). DCEP improves the MBE by approx. $1 \mathrm{~K}$ at

Table 1: Parameters of the grid cells that include Berlin's weather stations: the urban fraction $f_{\text {urb}}$, street width $W$, building width $B$ and the

\begin{tabular}{|c|c|c|c|c|c|c|c|c|c|c|}
\hline \multirow[b]{2}{*}{ Site } & \multirow[b]{2}{*}{$f_{\text {urb }}$} & \multirow[b]{2}{*}{$W / \mathrm{m}$} & \multirow[b]{2}{*}{$B / \mathrm{m}$} & \multicolumn{7}{|c|}{$\gamma_{i}$} \\
\hline & & & & $0 \mathrm{~m}$ & $5 \mathrm{~m}$ & $10 \mathrm{~m}$ & $15 \mathrm{~m}$ & $20 \mathrm{~m}$ & $25 \mathrm{~m}$ & $30 \mathrm{~m}$ \\
\hline Alexanderplatz & 0.69 & 29.8 & 14.7 & 0.00 & 0.03 & 0.02 & 0.04 & 0.19 & 0.41 & 0.26 \\
\hline Dahlem & 0.32 & 20.6 & 10.0 & 0.01 & 0.17 & 0.62 & 0.20 & 0.00 & 0.00 & 0.00 \\
\hline Tegel & 0.26 & 25.2 & 3.4 & 0.01 & 0.37 & 0.29 & 0.29 & 0.04 & 0.00 & 0.00 \\
\hline Tempelhof & 0.14 & 13.8 & 0.2 & 0.00 & 0.26 & 0.74 & 0.00 & 0.00 & 0.00 & 0.00 \\
\hline
\end{tabular}
building height distribution $\gamma_{i}$. 
Table 2: Root-mean-square error (first columns) and mean-bias error (second columns) of the hourly $2 \mathrm{~m}$ temperature values in K based on a simulation period of one week. The values for the reference simulation with DCEP are written in an upright font while the corresponding values of simulations in which Berlin is only represented by the bulk approach is written italic.

\begin{tabular}{ccccccc}
\hline Start date & Lindenberg & Alex. & Tegel & Tempelhof & Dahlem & Schönefeld \\
\hline $2002 / 07 / 28$ & $2.3 / 0.0$ & $2.0 / 0.0$ & $2.0 / 0.3$ & $2.5 / 0.5$ & $2.5 / 1.4$ & $2.2 / 0.8$ \\
& $2.3 / 0.0$ & $2.4 /-1.0$ & $2.1 /-0.1$ & $2.2 / 0.2$ & $2.0 / 0.7$ & $2.2 / 0.7$ \\
$2003 / 08 / 01$ & $1.1 / 0.6$ & $0.9 /-0.3$ & $1.2 /-0.3$ & $1.2 / 0.1$ & $2.1 / 1.0$ & $1.4 / 0.8$ \\
& $1.1 / 0.6$ & $1.7 /-1.3$ & $1.4 /-0.8$ & $1.0 /-0.4$ & $1.3 / 0.0$ & $1.3 / 0.7$ \\
$2006 / 07 / 01$ & $2.4 / 1.7$ & $2.5 / 1.4$ & $2.5 / 1.4$ & $2.6 / 1.4$ & $3.7 / 2.9$ & $3.0 / 2.1$ \\
& $2.4 / 1.7$ & $2.5 / 0.5$ & $2.4 / 0.9$ & $2.5 / 1.3$ & $3.2 / 2.5$ & $2.9 / 2.0$ \\
$2006 / 07 / 17$ & $1.9 /-0.2$ & $1.6 /-0.5$ & $1.9 / 0.0$ & $1.7 /-0.2$ & $2.9 / 1.6$ & $2.2 / 0.4$ \\
& $1.8 /-0.2$ & $2.2 /-1.4$ & $1.9 /-0.4$ & $1.6 /-0.5$ & $2.3 / 1.0$ & $2.1 / 0.3$ \\
$2008 / 07 / 24$ & $2.3 /-1.2$ & $2.1 /-1.6$ & $2.1 /-1.7$ & $2.2 /-1.5$ & $1.8 /-0.3$ & $2.1 /-1.2$ \\
& $2.3 /-1.2$ & $2.9 /-2.4$ & $2.5 /-2.1$ & $2.3 /-1.7$ & $1.9 /-1.1$ & $2.2 /-1.3$ \\
\hline
\end{tabular}

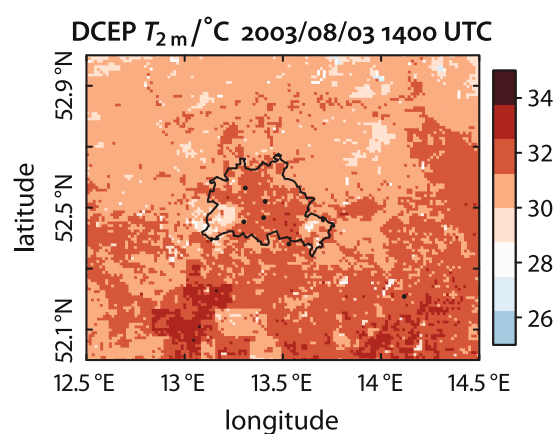

(a)

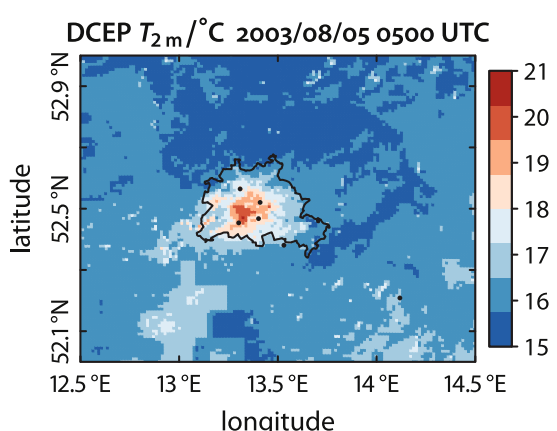

(b)

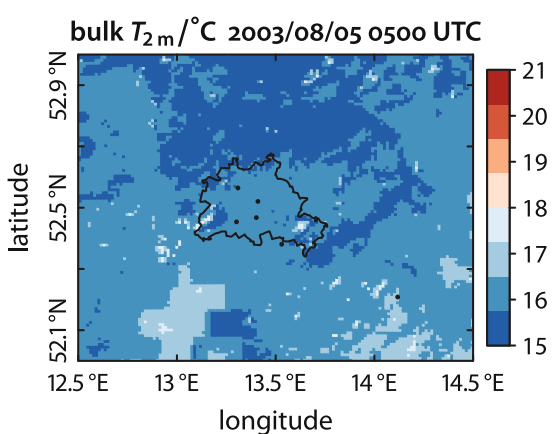

(c)

Figure 4: Typical spatial distributions of $T_{2 \mathrm{~m}}$ at a resolution of $1 \mathrm{~km}$ (the area of Berlin is outlined in black). In (a), a daytime distribution from 2003/08/03 at 1400 UTC is shown simulated with CCLM/DCEP, while (b) and (c) show the nighttime distribution of 2003/08/05 at 0500 UTC, simulated with CCLM/DCEP and with the bulk approach of CCLM, respectively.

the Alexanderplatz station. The exception is the 2006 EHE where the model is generally to warm (MBE $1.7 \mathrm{~K}$ at rural Lindenberg) and the bulk approach at the grid cell of Alexanderplatz compensate this with too cool temperatures. The measurements at Tegel, Tempelhof and Schönefeld sites are slightly, and at the Dahlem site clearly better represented by the bulk scheme. The observations at the latter sites represent the natural surfaces and open areas in their immediate vicinity, and not the mix of urban and natural surfaces calculated by CCLM/DCEP as grid cell averages. Both temperatures can differ substantially. ELIASSON (1996) for example found a difference of up to $2.5 \mathrm{~K}$ between temperatures measured in a street canyon and in an open area $400 \mathrm{~m}$ away from street canyon in the city centre of Göteborg, Sweden, during clear nights. Furthermore, PETERSON (2003) analysed homogenized temperature measurements of 289 stations in the USA in the years 1989-1991 and found no statistically significant impact of urbanization over the contiguous USA. The author suggests that this is due to the dominance of the micro and local scale effects over the mesoscale urban heat island since urban meteorological observations are likely to be made within parks.
The bulk scheme, however, is not able to reproduce the urban heat island during the night. Figure 4 shows typical spatial distributions of $T_{2 \mathrm{~m}}$ simulated with the bulk approach of CCLM and with DCEP. While no considerably higher urban temperatures are simulated during the day by either approach (only the simulation with DCEP is shown), the urban area is on average clearly warmer than the surrounding rural area during the night with DCEP. DCEP generates UHI values of up to $5.5 \mathrm{~K}$ during the depicted night. The bulk scheme, however, features only a small urban heat island of up to $1 \mathrm{~K}$. This scheme does not account for the larger heat capacity of the urban surfaces resulting in an underestimation of the storage flux during daytime. For example, DCEP simulates a grid cell average storage flux of up to $230 \mathrm{~W} \mathrm{~m}^{-2}$ in Berlin's centre during the day before the depicted UHI in Figure $4 \mathrm{~b}$ whereas the bulk scheme shows only values up to $150 \mathrm{~W} \mathrm{~m}^{-2}$. Thus, less energy can be released with the bulk scheme during nighttime, which results in an underestimation of the sensible heat flux. During the exemplary night $2003 / 08 / 05$, DCEP produces a minimum storage flux of $-170 \mathrm{~W} \mathrm{~m}^{-2}$ in the city centre with a sensible heat flux of up to $70 \mathrm{~W} \mathrm{~m}^{-2}$ whereas the bulk scheme shows a minimum storage flux 


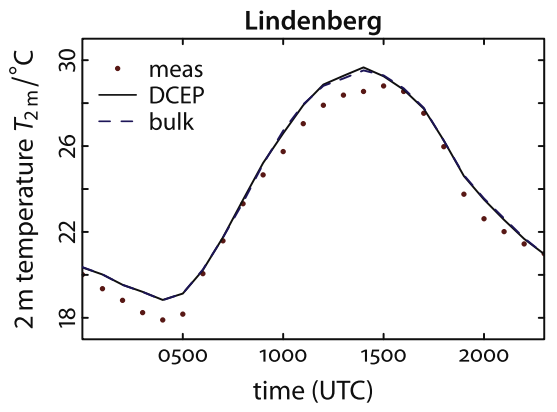

(a)

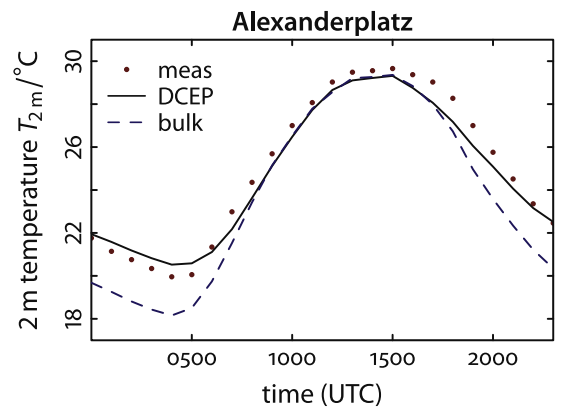

(b)

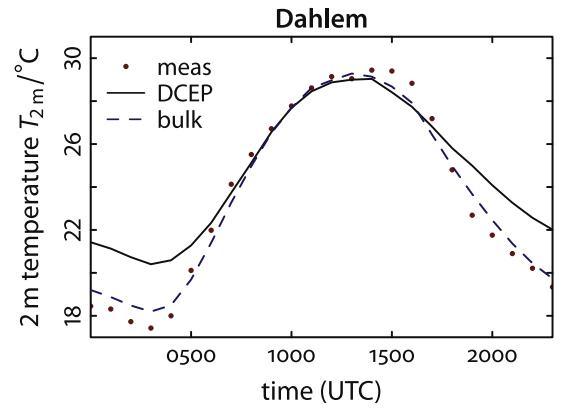

(c)

Figure 5: Simulated and observed $T_{2 \mathrm{~m}}$ for (a) Lindenberg, (b) Berlin-Alexanderplatz and (c) Berlin-Dahlem for the 2003 EHE.

of $-85 \mathrm{~W} \mathrm{~m}^{-2}$, which is accompanied by a smaller sensible heat flux of $-20 \mathrm{~W} \mathrm{~m}^{-2}$.

This is confirmed by the average diurnal cycle of $T_{2 \mathrm{~m}}$ for the 2003 period at Lindenberg, Alexanderplatz and Dahlem depicted in Figure 5. While the largest difference between measurement and simulation with DCEP at Dahlem is approx. $3.2 \mathrm{~K}$, the agreement at the other stations is better (see also Table 2). In particular, the measurements at Alexanderplatz, which exemplify the urban heat island of Berlin, is much better represented by DCEP than by the bulk approach during the night. During the day, both approaches produce similar results.

In the following, the dependence of the simulated $2 \mathrm{~m}$ temperature in Berlin on the urban parameters is analysed. For that purpose, the UHI intensity $\Delta T_{\mathrm{UHI}}$ for any grid cell in Berlin with $f_{\text {urb }}>0$ is defined as the difference in the $2 \mathrm{~m}$ temperature of that grid cell and that of the grid cell of Lindenberg:

$$
\Delta T_{\mathrm{UHI}}=T_{2 \mathrm{~m}}-T_{2 \mathrm{~m}}^{\mathrm{Lindenberg}} .
$$

For every EHE and every specific hour of the day, $\Delta T_{\mathrm{UHI}}$ is averaged over the analysed days of the EHE. The resulting distributions of the averaged $\Delta T_{\mathrm{UHI}}$ are fitted to different regression models. The urban fraction $f_{\text {urb }}$ is expected to be the most important parameter because it directly influences the averaging of urban and natural fluxes; with increasing $f_{\text {urb }}$ the heat island intensity is expected to increase. Furthermore, the urban effects should be more pronounced for larger buildings and narrower streets. OKE (1981) found for Australian, European and North American cities that the maximum urban heat island intensity increases with $\ln \lambda_{\mathrm{s}}$, where $\lambda_{\mathrm{s}}$ is the typical buildingheight-to-canyon-width ratio for the city with $\lambda_{\mathrm{s}} \equiv h / W$. Thus, the following models are used to fit the distributions by a least squares method, weighting each point with its variance resulting from the hourly average:

$$
\begin{aligned}
& \Delta T_{\mathrm{UHI}}^{(\mathrm{a})}=m_{f}^{(\mathrm{a})} f_{\mathrm{urb}} \quad+n^{(\mathrm{a})}, \\
& \Delta T_{\mathrm{UHI}}^{(\mathrm{b})}=m_{f}^{(\mathrm{b})} f_{\mathrm{urb}}+m_{h}^{(\mathrm{b})} h+n^{(\mathrm{b})},
\end{aligned}
$$

$$
\begin{aligned}
& \Delta T_{\mathrm{UHI}}^{(\mathrm{c})}=m_{f}^{(\mathrm{c})} f_{\mathrm{urb}}+m_{W}^{(\mathrm{c})} \frac{1}{W}+n^{(\mathrm{c})}, \\
& \Delta T_{\mathrm{UHI}}^{(\mathrm{d})}=m_{f}^{(\mathrm{d})} f_{\mathrm{urb}}+m_{\ln \lambda}^{(\mathrm{d})} \ln \lambda_{\mathrm{s}}+n^{(\mathrm{d})}, \\
& \Delta T_{\mathrm{UHI}}^{(\mathrm{e})}=m_{f}^{(\mathrm{e})} f_{\mathrm{urb}}+m_{\lambda}^{(\mathrm{e})} \lambda_{\mathrm{s}}+n^{(\mathrm{e})},
\end{aligned}
$$

where $m_{\psi}^{(\mathrm{i})}$ is the slope of $\psi$ and $n^{(\mathrm{i})}$ is the intercept of model (i). Figure 6a compares the coefficients of determination, $R^{2}$, of all models for the 2003 EHE. All models explain the variance in the data reasonably well at nighttime $\left(R^{2}>0.6\right)$ while the fit is rather inconclusive at daytime $\left(R^{2}<0.3\right.$ at 1000 UTC). This is due to the fact that at that time of the day the UHI is less pronounced and the $2 \mathrm{~m}$ temperature depends less on the local urban parameters due to increased advection of air masses by higher wind speeds. Furthermore, the largest increase in $R^{2}$ relative to the simplest model in Equation (4.3a) is reached with the model in Equation (4.3e). In order to test how significant the increase is, an $F$-test is done with the null hypothesis that the sum of the squared residuals of the enhanced model in Equation (4.3e) is equal to that of the basic model in Equation (4.3a) and the alternative hypothesis that this sum is lower for the enhanced model than for the basic model. The null hypothesis is rejected (i.e. the enhanced model reduces this sum significantly) throughout the day except at 0800 UTC, and at 1700 UTC and at 1800 UTC. Thus, the model in Equation (4.3e) is studied in more detail.

The value of the slopes $m_{f} \equiv m_{f}^{(\mathrm{e})}$ and $m_{\lambda} \equiv m_{\lambda}^{(\mathrm{e})}$ of the 2003 EHE are shown in Figure 6. Since, in general, the UHI intensity is greatest at night (e.g. OKE and MAXWEll, 1975; UNWIN, 1980; ADEBAYO, 1987; MAGEE et al., 1999; FORTUNIAK et al., 2006), $m_{f}$ is larger during the night (approx. $3 \mathrm{~K}$ ) than during the day (less then $1.5 \mathrm{~K}$ ). Throughout the whole day, $t$-tests confirm that $m_{f}$ is significantly different from zero. Interestingly, the slope $m_{\lambda}$ changes the sign during the day.

At nighttime, $m_{\lambda}$ is positive, thus, the UHI intensity increases with $\lambda_{\mathrm{s}}$ due to the increased amount of heat stored in the urban surfaces and due to the reduced sky visibility inside the street canyon. At noon, however, 


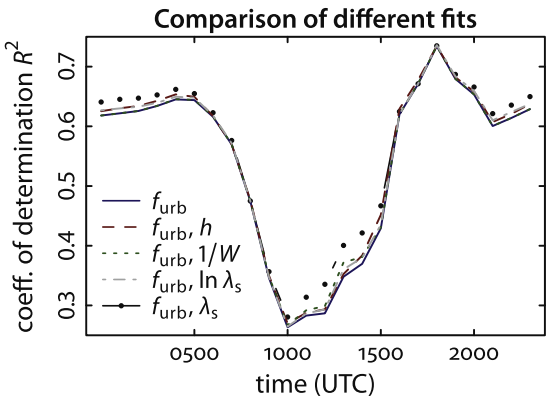

(a)

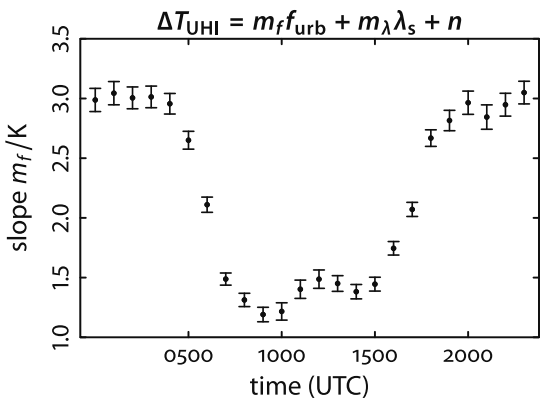

(b)

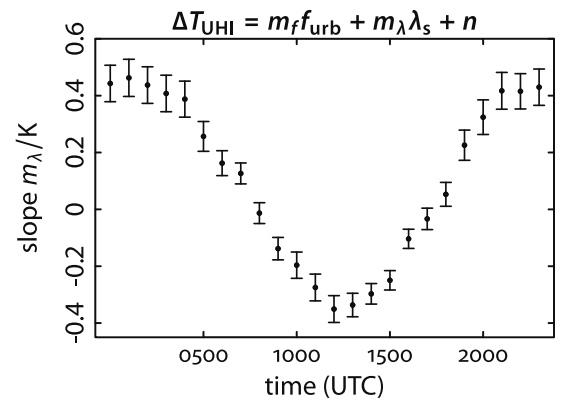

(c)

Figure 6: Results of the fit of the average urban heat island intensity $\Delta T_{\text {UHI }}$ for the 2003 EHE. While Fig. (a) compares the coefficient of determination of all models in Equation (4.3), Fig. (b) and (c) show the regression coefficients of the model in Equation (4.3e) with the respective standard deviation marked with error bars.

$m_{\lambda}$ is negative indicating that temperatures are lower at the $2 \mathrm{~m}$ level with larger $\lambda_{\mathrm{s}}$. This is due to the fact that more energy is being stored in the urban surface and the shadowing effect of the urban lower level surfaces is increased. $m_{\lambda}$ is significantly different from zero except at the times of its zero crossing. Furthermore, the general behaviour of $m_{\lambda}$ agrees with the results of the sensitivity studies of HAMDI and SCHAYES (2008) and MARCIOTTO et al. (2010). Instead of the analysis of the spatial distribution of the UHI, both papers analysed the effect of varying $\lambda_{\mathrm{s}}$ for one street canyon. HAMDI and SCHAYES (2008) used a mesoscale model with BEP in a 1-D column mode forced with measurements from the Basel in June 2002. At nighttime, they found up to $0.8 \mathrm{~K}$ cooler canyon temperatures with $\lambda_{\mathrm{s}}=0.43$ and up to $0.25 \mathrm{~K}$ warmer canyon temperatures with $\lambda_{\mathrm{s}}=1.5$ compared with a simulation of $\lambda_{\mathrm{s}}=1$. At daytime, the results were reversed with an increase of up to $0.62 \mathrm{~K}$ for $\lambda_{\mathrm{s}}=0.43$ and a decrease of up to $0.4 \mathrm{~K}$ for $\lambda_{\mathrm{s}}=1.5$ in the canyon temperature. MARCIOTTO et al. (2010) used a similar approach with an independent implementation of the TEB scheme (MASSON, 2000) forced with typical summer measurements at a micrometeorological station at the University of São Paulo, Brazil, and varied $\lambda_{\mathrm{s}}$ from 0.5 to 10 . At 1200 local time, they found a decrease of the canyon temperature corresponding to a slope of $m_{\lambda} \approx-0.55 \mathrm{~K}$ for $\lambda_{\mathrm{s}} \leq 5$ and a slightly smaller $m_{\lambda}$ for higher $\lambda_{\mathrm{s}}$. At 0000 local time, they found $m_{\lambda} \approx 1 \mathrm{~K}$ for $\lambda_{\mathrm{s}} \leq 3$; for large $\lambda_{\mathrm{s}} \geq 5$, they found a decrease of canyon temperatures as $\lambda_{\mathrm{s}}$ increases further similar to the night with $m_{\lambda} \approx-0.4$.

The intercept $n$ (not shown) is negative and significantly different from zero throughout the day. Its value depends mainly on the chosen reference grid cell. Lindenberg, located south-east of Berlin, is usually warmer than the rural area north of Berlin (cf. Figure 4b) resulting in the negative value of $n$.

Furthermore, Table 3 lists the results of the fit for all other analysed EHEs at 0100 UTC (nighttime with $m_{\lambda}>0$ ) and at 1200 UTC (daytime with $m_{\lambda}<0$ ). These results support the findings for the 2003 EHE.

\subsection{Assessment of the parameter influence}

In this section, the effect of the modifications of the natural surface fraction $f_{\text {nat }}$ and the roof albedo $\alpha_{\mathrm{R}}$ on the $2 \mathrm{~m}$ temperature is analysed. In order to provide a better context for these findings, the corresponding changes in the urban fraction $f_{\text {urb }}$ and in the total, grid cell averaged albedo $\alpha$ are determined beforehand.

The spatial distribution of the change in the urban fraction, $\Delta f_{\text {urb }}$, resulting from a modified natural surface fraction $f_{\text {nat }}$ can be derived directly from the spatial distribution of $f_{\text {urb }}$ : A relative change of the natural surface fraction by $\delta f_{\text {nat }}$ implies a change in the urban fraction of

$$
\Delta f_{\text {urb }}\left(\delta f_{\text {nat }}\right)=-\Delta f_{\text {nat }}\left(\delta f_{\text {nat }}\right)=-\left(1-f_{\text {urb }}\right) \delta f_{\text {nat }} .
$$

Thus, the larger $f_{\text {urb }}$ in Figure 2a the smaller $\Delta f_{\text {urb }}$. The calculation of the change in the grid cell averaged albedo, $\Delta \alpha$, due to an increased roof albedo $\alpha_{R}$ is slightly more complicated. A larger $\alpha_{R}$ increases the urban albedo for diffuse and direct radiation separately depending on the urban canopy parameters. Consequently, the respective grid cell averaged values are modified. Furthermore, due to the effect of these changes on the meteorological state variables, the soil water content is modified by a small amount, which results in a slightly different albedo of natural surfaces as well. Figure $7 \mathrm{a}$ and Figure $7 \mathrm{~b}$ depict the average spatial distribution of the change of the total urban and total grid cell averaged albedo, $\Delta \alpha_{\text {urb }}$ and $\Delta \alpha$, respectively, at 1200 UTC for the 2003 EHE. The histogram of $\Delta \alpha$ for this EHE is shown in Figure $7 \mathrm{c}$. While $\Delta \alpha_{\text {urb }}$ is relatively homogeneously distributed over the area of Berlin, $\Delta \alpha$ is clearly larger in the city centre due to the larger urban fraction there. The average $\Delta \alpha$ of the urban grid cells of Berlin is about 0.07 . Similar results are found for other times of the day with large insolation and also for the other EHEs.

Figure 8 shows the average $\Delta T_{2 \mathrm{~m}}$ in response to $\mathrm{V}-25, \mathrm{~V}+05, \mathrm{~V}+15$, AR40, AR65 and VAR for the 2003 EHE at the grid cells of Alexanderplatz and Dahlem as well as the average spatial distribution of $\Delta T_{2 \mathrm{~m}}$ for 
Table 3: Results of the linear regression with the model in Equation (4.3e) for all analysed extreme heat events. Listed are the regression coefficients $m_{f}, m_{\lambda}$ and $n$ with their respective standard deviations as well as the coefficient of determination, $R^{2}$. Not shown is that all regression coefficients are significantly different from zero except $m_{\lambda}$ for the 2008 EHE at 1200 UTC.

\begin{tabular}{|c|c|c|c|c|c|c|c|c|}
\hline \multirow[b]{2}{*}{ Start date } & \multicolumn{4}{|c|}{ Averaged at $0100 \mathrm{UTC}$} & \multicolumn{4}{|c|}{ Averaged at $1200 \mathrm{UTC}$} \\
\hline & $m_{f} / \mathrm{K}$ & $m_{\lambda / \mathrm{K}}$ & $n / \mathrm{K}$ & $R^{2}$ & $m_{f} / \mathrm{K}$ & $m_{\lambda / \mathrm{K}}$ & $n / \mathrm{K}$ & $R^{2}$ \\
\hline $2002 / 07 / 28$ & $2.47 \pm 0.05$ & $0.22 \pm 0.04$ & $-0.54 \pm 0.03$ & 0.78 & $1.63 \pm 0.06$ & $-0.19 \pm 0.04$ & $0.16 \pm 0.03$ & 0.54 \\
\hline $2003 / 08 / 01$ & $3.04 \pm 0.10$ & $0.46 \pm 0.07$ & $-1.05 \pm 0.05$ & 0.65 & $1.49 \pm 0.08$ & $-0.35 \pm 0.05$ & $-0.93 \pm 0.04$ & 0.34 \\
\hline $2006 / 07 / 01$ & $2.66 \pm 0.07$ & $0.55 \pm 0.05$ & $-0.25 \pm 0.04$ & 0.75 & $1.25 \pm 0.10$ & $-0.17 \pm 0.06$ & $-0.38 \pm 0.05$ & 0.20 \\
\hline $2006 / 07 / 17$ & $2.89 \pm 0.09$ & $0.47 \pm 0.05$ & $-0.38 \pm 0.04$ & 0.70 & $1.28 \pm 0.09$ & $-0.26 \pm 0.06$ & $-0.22 \pm 0.04$ & 0.23 \\
\hline $2008 / 07 / 24$ & $2.73 \pm 0.10$ & $0.43 \pm 0.07$ & $-0.56 \pm 0.05$ & 0.58 & $1.12 \pm 0.08$ & $-0.06 \pm 0.05$ & $-0.23 \pm 0.04$ & 0.23 \\
\hline
\end{tabular}

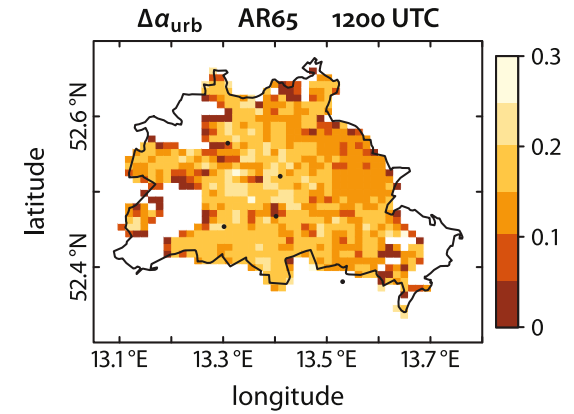

(a)

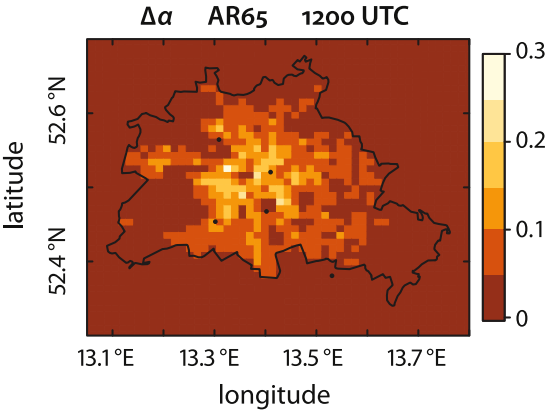

(b)

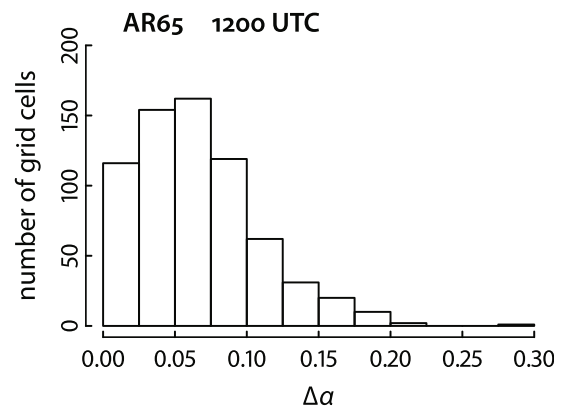

(c)

Figure 7: Average increase of the total average albedo in the AR65 run compared to the reference simulation at 1200 UTC during the 2003 EHE. In (a), the albedo difference in the urban part of the grid cell, $\Delta \alpha_{\text {urb }}$, is depicted, while in (b) and (c), the average albedo difference of the complete mesoscale grid cell, $\Delta \alpha$, is shown.

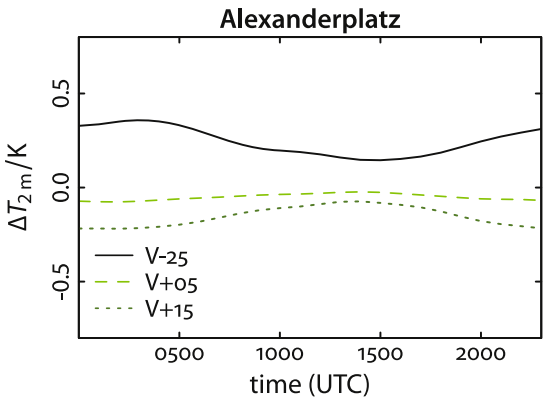

(a)

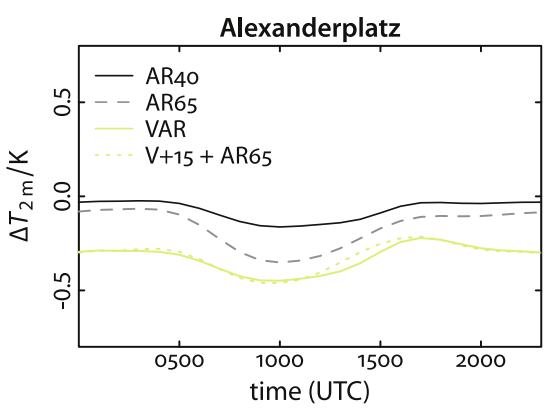

(b)

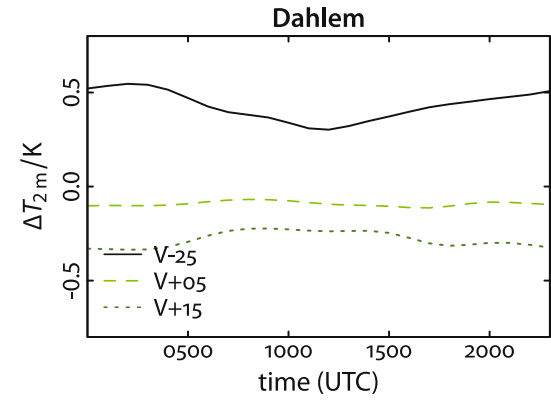

(c)

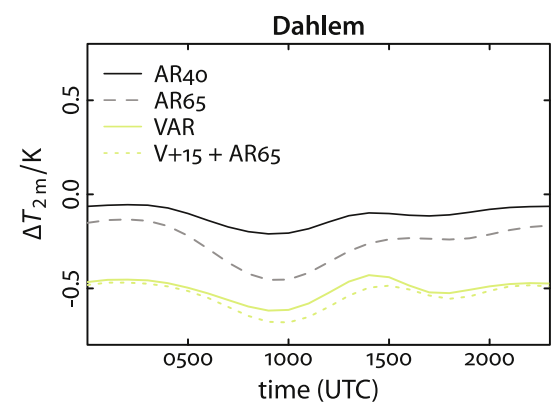

(d)

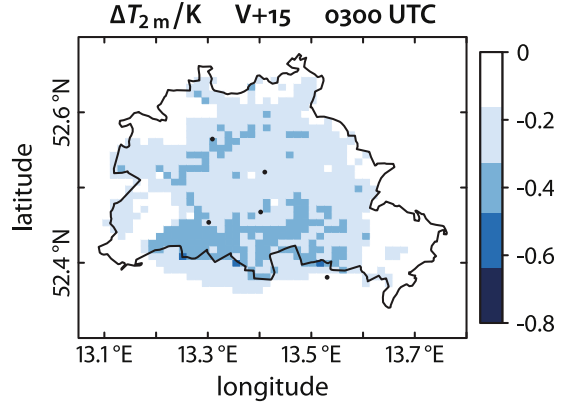

(e)

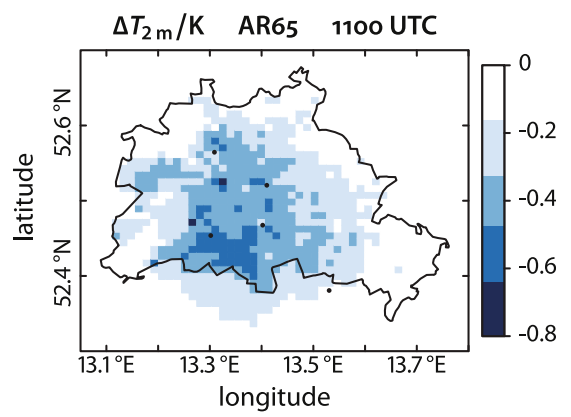

(f)

Figure 8: Average response to the modified parameters for the $2003 \mathrm{EHE}$ : In (a)-(d), the simulated average $\Delta T_{2 \mathrm{~m}}$ between the simulations with modified vegetation cover and albedo and the reference simulation is shown for the Alexanderplatz and Dahlem grid cell. In Fig. (e) (Fig. (f)), the average spatial distribution of $\Delta T_{2 \mathrm{~m}}$ between $\mathrm{V}+15$ (AR65) and the reference simulation at 0300 UTC (1100 UTC) is depicted (the area of Berlin is outlined in black). 
Table 4: Maximum average change in $2 \mathrm{~m}$ temperature in $\mathrm{K}$ derived from the average diurnal course of $\Delta T_{2 \mathrm{~m}}$ for each urban station. Rows represent the five analysed extreme heat events in order of their occurrence.

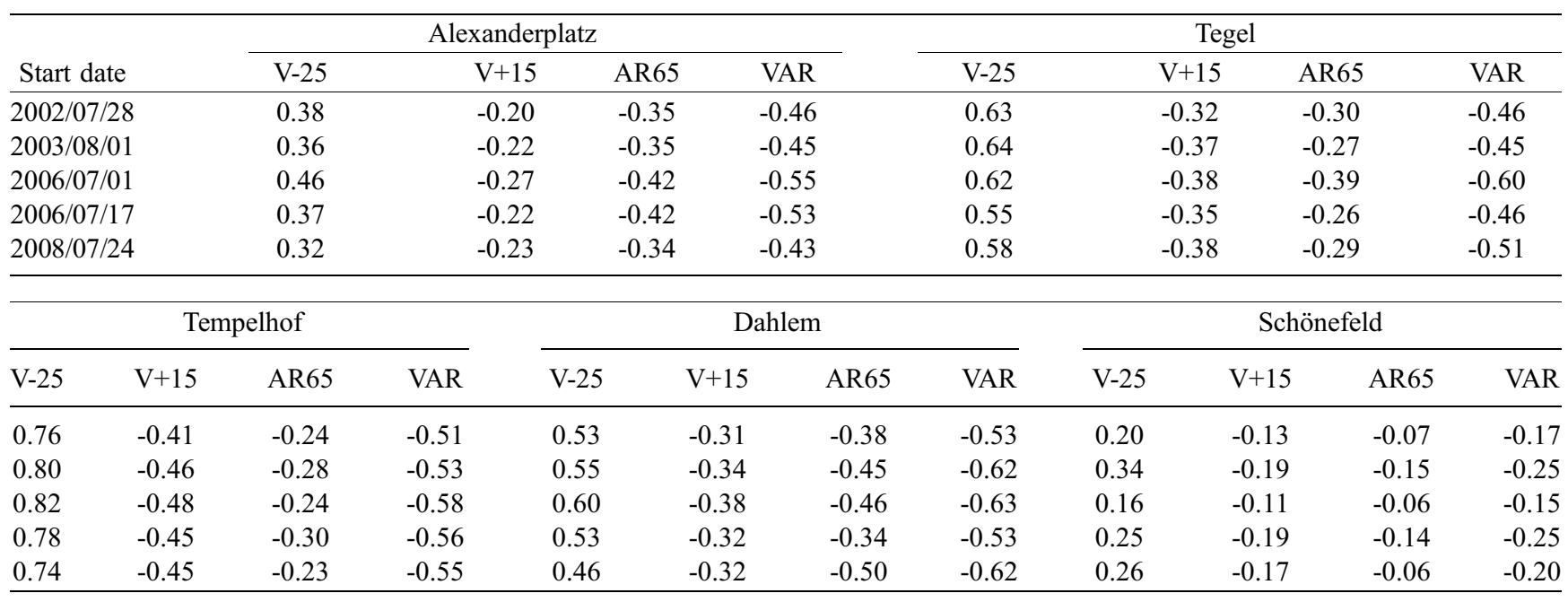

Table 5: Expected maximum average change in $2 \mathrm{~m}$ temperature in $\mathrm{K}$ derived from the slope $m_{f}$ of reference simulation for each urban station. Rows represent the five analysed extreme heat events in order of their occurrence.

\begin{tabular}{|c|c|c|c|c|c|c|c|c|}
\hline \multirow[b]{2}{*}{ Start date } & \multicolumn{2}{|c|}{ Alexanderplatz } & \multicolumn{2}{|c|}{ Tegel } & \multicolumn{2}{|c|}{ Tempelhof } & \multicolumn{2}{|c|}{ Dahlem } \\
\hline & $\mathrm{V}-25$ & $\mathrm{~V}+15$ & $\mathrm{~V}-25$ & $\mathrm{~V}+15$ & $\mathrm{~V}-25$ & $\mathrm{~V}+15$ & $\mathrm{~V}-25$ & $\mathrm{~V}+15$ \\
\hline $2002 / 07 / 28$ & 0.19 & -0.11 & 0.46 & -0.27 & 0.53 & -0.32 & 0.42 & -0.25 \\
\hline 2003/08/01 & 0.24 & -0.14 & 0.56 & -0.34 & 0.65 & -0.39 & 0.52 & -0.31 \\
\hline 2006/07/01 & 0.21 & -0.12 & 0.49 & -0.30 & 0.57 & -0.34 & 0.45 & -0.27 \\
\hline 2006/07/17 & 0.22 & -0.13 & 0.53 & -0.32 & 0.62 & -0.37 & 0.49 & -0.29 \\
\hline $2008 / 07 / 24$ & 0.21 & -0.13 & 0.51 & -0.30 & 0.59 & -0.35 & 0.46 & -0.28 \\
\hline
\end{tabular}

$\mathrm{V}+15$ and AR65. The time series has been filtered with a binomial filter with a length of $7 \mathrm{~h}$ to suppress high frequency noise (MITCHELL et al., 1966). Furthermore, for each EHE the maximum average changes in $T_{2 \mathrm{~m}}$ derived from the average diurnal course of $\Delta T_{2 \mathrm{~m}}$ for each urban station is shown in Table 4.

In the considered model grid cells, VAR has the largest cooling effect on $T_{2 \mathrm{~m}}$ (up to $0.81 \mathrm{~K}$ at Dahlem). For the single parameter runs, AR65 causes the largest cooling (up to $0.63 \mathrm{~K}$ at Dahlem) while V-25 leads to an increase in $T_{2 \mathrm{~m}}$ of up to $0.80 \mathrm{~K}$ at Tempelhof.

The largest average $\Delta T_{2 \mathrm{~m}}$ of the runs with increased natural surface fraction is simulated during the night. While V-25 leads to an increase in $T_{2 \mathrm{~m}}$ of up to $0.82 \mathrm{~K}$ in the grid cells of Tempelhof and up to $0.60 \mathrm{~K}$ in the grid cell Dahlem, $\mathrm{V}+15$ decreases the temperature by up to $0.48 \mathrm{~K}$ and $0.38 \mathrm{~K}$ in these grid cells. In general, a higher natural surface fraction implies a lower urban fraction and, consequently, a reduction of the total heat storage capacity as well as a reduction of radiation trapping. During daytime, the latent heat flux is larger implying that less energy is available to heat the near-surface air. This behaviour is similar to the UHI effect in Berlin which is stronger during the night than during the day. In particular, it can be compared to the temperature change derived from the UHI analysis of the reference simulation in the previous section. With Equation (4.4), the UHI model in Equation (4.3e) would result in a change of temperature of

$$
\Delta T_{2 \mathrm{~m}}^{\text {estimate }}=\Delta f_{\text {urb }} m_{f}=-\left(1-f_{\text {urb }}\right) \delta f_{\text {nat }} m_{f} .
$$

Table 5 lists the corresponding temperature changes. These values underestimate the simulated changes for V-25 and V+15 in Table 4. Especially, at the Alexanderplatz station, the simulated temperature change is about twice as large as the one estimated with Equation (4.5). Here, the small local absolute change $\Delta f_{\text {nat }}$ of the mesoscale grid cell at the Alexanderplatz station is accompanied by larger changes of the surrounding grid cells, which increases the effect. $\Delta f_{\text {urb }}$ is larger at the other stations, thus yielding a better estimate there.

As expected, the largest effect of the increased roof albedo is detected during midday when the incoming solar radiation is largest. Here, a cooling of up to $0.46 \mathrm{~K}$ is detected at the grid cell of Dahlem, while Alexanderplatz is cooler by up to $0.42 \mathrm{~K}$. In general, the effects of AR40 and AR65 are stronger for the Dahlem than for the Alexanderplatz grid cell, which is characterized by a larger $f_{\text {urb }}$ value and therefore roof 
area. This can be explained by the predominant simulated wind direction. During the EHEs in 2003 and 2008, the wind direction is mainly north to northeast; in 2002 and 2006, this is the case about half of the time. The Dahlem station, which is located in the southern part of the city, benefits from the accumulated effect of $\Delta T_{2 \mathrm{~m}}$ in a large part of the urban area. Figure $8 \mathrm{f}$ indicates a north south gradient along the wind direction and advection of the cooler air into the rural area south of the city.

Interestingly, the averaged $\Delta T_{2 \mathrm{~m}}$ of the VAR is similar to the sum of $\Delta T_{2 \mathrm{~m}}$ of the $\mathrm{V}+15$ and AR65 runs. This indicates that the cooling effects of an increased vegetation fraction and an increased roof albedo add up when measured at a height of $2 \mathrm{~m}$.

\section{Summary and conclusion}

This paper was devoted to estimating the effect of green areas and roof albedos on air temperatures in Berlin, Germany, during extreme heat events (EHE). Five EHEs were identified in the considered years 2000-2009. For each EHE, a reference simulation with CCLM/DCEP was conducted representing the meteorology at that time. To this end, urban canopy parameters (UCPs) were derived based on highly detailed 3-D building and land surface data. As opposed to relying on land-use data only, this method produces urban parameters of higher spatial resolution and circumvents a rough assignment to classes. Thus, it is likely to produce a more realistic description of the ensemble of urban surfaces. Furthermore, building data-sets for an increasing number of cities will likely be available in the future. The approaches presented here can be further adjusted to these data-sets to provide UCPs for future high resolution mesoscale simulations.

From the reference simulations, it was concluded that the CCLM/DCEP model performs well in terms of the root-mean-square error (RMSE) and the mean-bias error (MBE) of the $2 \mathrm{~m}$ temperature. Both error measures behave similarly at the rural station Lindenberg (which is practically not influenced by DCEP) and the urban station Alexanderplatz in the centre of Berlin. This indicates a consistent interplay of DCEP with CCLM since these two stations are representative of the rural and urban characteristics, respectively. At the other urban stations, however, the bulk scheme performs better due to large green areas dominating the station's surroundings. Therefore, these station measurements are not comparable with the simulated grid cell average temperature of urban and natural surfaces. An extreme example is the Dahlem station measurement for the EHE of 2003 displaying a temperature even lower than at the Lindenberg site. Furthermore, the bulk scheme does not produce an urban heat island (UHI).

Within the DCEP reference simulations, the UHI was analysed considering a linear dependence on the urban fraction and the height-to-width ratio. At nighttime, this linear model describes the UHI well. As expected, the UHI increases with rising urban fraction and heightto-width ratio. At daytime, in contrast, the UHI effect is very weak and the linear model is insufficient in describing the temperature distribution. Still, the findings indicate a small increase of temperature with rising urban fraction but a decrease of temperature with rising heightto-width ratio. With higher buildings and narrower streets, the shadowing of the lower urban surfaces is increased leading to lower near-surface air temperatures.

By varying the natural surface fraction, the influence of green areas on the $2 \mathrm{~m}$ temperatures is investigated. A natural surface fraction decreased by $25 \%$ for all mesoscale grid cells of Berlin results in an up to $0.82 \mathrm{~K}$ larger $2 \mathrm{~m}$ temperature at the urban stations. An increase of the natural surface fraction by $15 \%$ shows a cooling of up to $0.48 \mathrm{~K}$. This effect is more pronounced at nighttime due to the difference in the total heat storage capacity and the radiation trapping capability associated with a change of the urban fraction. In general, a stronger effect is observed than the reference simulation would imply by a change of the urban fraction in the linear model. This is because the linear model only considers the local urban parameters, whereas for the variation of the natural surface fraction all urban grid cells were modified. Hence, a modification of the natural surface fraction of only one grid cell might be better represented by the linear model.

An increased albedo of roof surfaces directly reproduces the effect of high-albedo surface coatings. In the simulation with a roof albedo of 0.65 , up to $0.5 \mathrm{~K}$ lower $2 \mathrm{~m}$ temperatures were detected at the urban stations compared with the reference simulation with a roof albedo of about 0.16 . This effect is as expected stronger during daytime. However, the largest change was not detected in the city centre but in the outskirts due to the advection of cool air towards that region. This advection of cool air was also seen in the study by TAHA (2008) for Sacramento (California, USA). Due to the larger insolation at Sacramento, and an increase of the albedo not only of the roofs but also of wall and street surfaces, a lower $2 \mathrm{~m}$ temperature of up to $3 \mathrm{~K}$ was found. ROSENZWEIG et al. (2009), in turn, found temperature changes similar to this analysis (up to $0.6 \mathrm{~K}$ ) in their study for New York City (USA). KRAYENHOFF and VOOGT (2010) summarized further studies and found a peak daytime air temperature reduction on the order of $0.5 \mathrm{~K}$ for typical clear-sky midlatitude summer conditions for a 0.1 average increase in the neighbourhoodscale albedo. In this study, however, a grid cell dependent temperature change results from grid cell dependent albedo increases, but also taking advection into consideration. It is therefore difficult to spatially correlate a specific temperature change with a corresponding albedo increase. Nonetheless, the simulation with a roof albedo of 0.65 can be interpreted to yield a cooling that is roughly consistent with the estimate in KRAYENHOFF and VOOGT (2010). 
Combining both, the increased natural surface fractions and higher roof albedos, results in temperature differences comparable to the sum of those of the single modifications. The maximum effects of the single modifications do not simply add up because they occur at different times of the day. Thus, the maximum cooling at the urban stations was found to be $0.63 \mathrm{~K}$. Even though these grid cell average changes appear small relative to the large scale natural surface fraction and albedo modifications assumed in the simulations, it needs to be pointed out that subgrid scale temperature changes can be more intense.

In general, field experiments analysing the local scale effects of city-scale urban heat island mitigation approaches cannot be performed, due to costs and logistics as well as the difficulty of creating a comparable reference scenario (KRAYENHOFF and VOOGT, 2010). Therefore, although UCMs might not exactly quantify the processes in the urban roughness layer, UCMs coupled to mesoscale models such as the CCLM are the best available tools for this kind of analysis due to the variety of scales involved (KRAYENHOFF and VOOGT, 2010). The online coupled CCLM/DCEP represents such a tool. Since DCEP is formulated in terms of physically explicit urban canopy parameters directly reflecting the real world, modified real world conditions like the building morphologies or the roof albedo can be directly implemented without having to propagate the effects to derived quantities such as the roughness length or albedo of the whole city.

\section{Acknowledgments}

We like to thank the city of Berlin for the supply of the 3-D Berlin data as well as the European Union for supporting the creation of this data through the European Regional Development Fund. Furthermore, the map of the impervious surface coverage of Berlin is based on data from the Urban and Environmental Information System of the Senate Department for Urban Development of Berlin.

\section{References}

ADEBAYO, Y.R., 1987: A note on the effect of urbanization on temperature in Ibadan. - J. Climatol. 7, 185-192.

BEST, M.J., 2005: Representing urban areas within operational numerical weather prediction models. - Bound.Layer Meteor. 114, 91-109.

BRETZ, S.E., H. AKBARI, 1997: Long-term performance of high-albedo roof coatings. - Energy Build. 25, 159-167.

DeE, D.P., S.M. UpPala, A.J. Simmons, P. BERrisford, P. Poli, S. Kobayashi, U. Andrae, M.A. Balmaseda, G. BAlsAmo, P. BAuer, P. BeChtold, A.C.M. BeljaARS, VAN DE L. BERG, J. BIDLOT, N. BORMANN, C. DELSOL, R. Dragani, M. Fuentes, A.J. GeER, L. Haimberger, S.B.
Healy, H. Hersbach, E.V. Hólm, L. Isaksen, P. KÅLlBERG, M. KÖHLER, M. MATRICARDI, A.P. MCNALLY, B.M. Monge-Sanz, J.-J. Morcrette, B.-K. Park, C. PEUBEy, DE P. Rosnay, C. TAVOlATO, J.-N. ThÉPAUT, F. VITART, 2011: The ERA-Interim reanalysis: configuration and performance of the data assimilation system. - Quart. J. Roy. Meteor. Soc. 137, 553-597.

Doms, G., J. Förstner, E. Heise, H.-J. Herzog, D. MIRONOV, M. RASCHENDORFER, T. REINHARDT, B. RitTer, R. Schrodin, J.-P. Schulz, G. Vogel, 2011: A Description of the Nonhydrostatic Regional COSMO Model. - Deutscher Wetterdienst.

ELIASSON, I., 1996: Intra-urban nocturnal temperature differences: a multivariate approach. - Climate Res. 7, 21-30.

FORTUNIAK, K., K. KŁYSIK, J. WIBIG, 2006: Urban-rural contrasts of meteorological parameters in Łódź. - Theo. Appl. Climatol. 84, 91-101.

HAMDI, R., G. SCHAYES, 2008: Sensitivity study of the urban heat island intensity to urban characteristics. - Int. J. Climatol. 28, 973-982.

Huth, R., J. KYSElÝ, L. POKORNÁ, 2000: A GCM simulation of heat waves, dry spells, and their relationships to circulation. - Climatic Change. 46, 29-60.

JUNG, I., 2009: Building reconstruction Berlin. - Reference report, virtualcity SYSTEMS.

KiKegawa, Y., Y. Genchi, H. YoshiKado, H. KondO, 2003: Development of a numerical simulation system toward comprehensive assessments of urban warming countermeasures including their impacts upon the urban buildings' Energy-demands. - Appl. Energy. 76, 449-466.

KRAYENHOFF, E.S., J.A. VOOGT, 2010: Impacts of urban albedo increase on local air temperature at daily-annual time scales: Model results and synthesis of previous work. - J. Appl. Meteor. Climatol. 49, 1634-1648.

LIU, Y., F. CHEN, T. WARNER, J. BASARA, 2006: Verification of a mesoscale data-assimilation and forecasting system for the Oklahoma City area during the joint urban 2003 field project. - J. Appl. Meteor. 45, 912-929.

Magee, N., J. CuRTIS, G. WendLeR, 1999: The urban heat island effect at Fairbanks, Alaska. - Theo. Appl. Climatol. 64, 39-47.

Marciotto, E.R., A.P. OliveirA, S.R. HANNA, 2010: Modeling study of the aspect ratio influence on urban canopy energy fluxes with a modified wall-canyon energy budget scheme. - Build. Environ. 45, 2497-2505.

MARTILLI, A., 2009: On the derivation of input parameters for urban canopy models from urban morphological datasets. - Bound.-Layer Meteor. 130, 301-306.

Martilli, A., A. Clappier, M.W. RotaCh, 2002: An urban surface exchange parameterisation for mesoscale models. Bound.-Layer Meteor. 104, 261-304.

MASSON, V., 2000: A physically-based scheme for the urban energy budget in atmospheric models. - Bound.-Layer Meteor. 94, 357-397.

MASSON, V., 2006: Urban surface modeling and the mesoscale impact of cities. - Theo. Appl. Climatol. 84, 35-45.

Masson, V., Y. Lion, A. Peter, G. Pigeon, J. Buyck, E. BRUN, 2012: "Grand Paris": regional landscape change to 
adapt city to climate warming. - Climatic Change, published online, http://link.springer.com/article/10.1007/ s10584-012-0579-1/fulltext.html.

MeEHL, G.A., C. TEBALDI, 2004: More intense, more frequent, and longer lasting heat waves in the 21 st century. - Science. 305, 994-997.

Mitchell, JR., J.M., B. DZERDZEevskit, H. FlOHN, W.L. HOFMEYR, H.H. LAMP, K.N. RAO, C.C. WALLÉN, 1966: Climatic change. - Technical Note 79, World Meteorological Organization.

OGC, 2008: OpenGIS City Geography Markup Language (CityGML) Encoding Standard. - Open Geospatial Consortium Inc.

OKE, T.R., 1981: Canyon geometry and the nocturnal urban heat island: Comparison of scale model and field observations. - J. Climatol. 1, 237-254.

OKE, T.R., G.B. MAXWELL, 1975: Urban heat island dynamics in Montreal and Vancouver. - Atmos. Environ. 9, 191-200.

PETERSON, T.C., 2003: Assessment of urban versus rural in situ surface temperatures in the contiguous United States: No difference found. - J. Climate. 16, 2941-2959.

RASCHENDORFER, M., 2012: Surface to atmosphere transfer: by vertical integration of effective gradient flux densities throughout the near surface transfer layer. - http://www. clm-community.eu/index.php?menuid $=171 \&$ downloadid $=$ 959\&reporeid $=0$.

Rockel, B., C.L. Castro, R.A. Pielke, Sr, von H. STORCH, G. LEONCINI, 2008: Dynamical downscaling: Assessment of model system dependent retained and added variability for two different regional climate models. - J. Geophys. Res. 113, D21107.

Roessner, S., K. Segl, M. Bochow, U. Heiden, W. HELDENS, H. KAUFMANN, 2011: Potential of hyperspectral remote sensing for analyzing the urban environment. - In: X. YANG (Ed.): Urban Remote Sensing. - WileyBlackwell.

Rosenzweig, C., W.D. Solecki, J. Cox, S. Hodges, L. PARShall, B. LYNN, R. GOLDBERG, S. GAFFIN, R.B. SlosberG, P. SAVio, M. WATson, F. Dunstan, 2009: Mitigating New York City's heat island: Integrating stakeholder perspectives and scientific evaluation. - Bull. Amer. Meteor. Soc. 90, 1297-1312.

SAILOR, D.J., N. DIETSCH, 2007: The urban heat island mitigation impact screening tool (mist). - Environ. Model. \& Software. 22, 1529-1541.

SalamancA, F., A. Martilli, C. YagüE, 2011: A numerical study of the urban heat island over Madrid during the DESIREX (2008) campaign with WRF and an evaluation of simple mitigation strategies. - Int. J. Climatol. 32, 2372-2386.

Schubert, S., S. Grossman-Clarke, A. Martilli, 2012: A double-canyon radiation scheme for multi-layer urban canopy models. - Bound.-Layer Meteor. 145, 439-468.

SmiateK, G., B. Rockel, U. SchÄtTler, 2008: Time invariant data preprocessor for the climate version of the COSMO model (COSMO-CLM). - Meteorol. Z. 17, 395405.

Steppeler, J., G. Doms, U. Schättler, H.W. Bitzer, A. GAssmanN, U. DAMrath, G. GREGORIC, 2003: Mesogamma scale forecasts using the nonhydrostatic model LM. - Meteor. Atmos. Phys. 82, 75-96.

TAHA, H., 2008: Meso-urban meteorological and photochemical modeling of heat island mitigation. - Atmos. Environ. 42, 8795-8809.

UnwIN, D.J., 1980: The synoptic climatology of Birmingham's urban heat island, 1965-74. - Weather. 35, 43-50. 